\title{
SABERES E PRÁTICAS NO CUIDADO AO RECÉM-NASCIDO EMTERAPIA INTENSIVA EM FLORIANÓPOLIS (DÉCADA DE 1980)
}

\author{
Knowl edge and practice in the care of a newborn on an intensive therapy in Florianopolis \\ (1980's)
Saberes y prácticas en el cuidado al recién nacido en terapia intensiva en Florianópolis (década de 1980)

Roberta Costa ${ }^{1}$

Maria Itayra Padilha

\section{RESUMO}

Pesquisa qualitativa, com abordagem sócio-histórica, cujo objetivo foi compreender a história das transformações das práticas de cuidado ao recém-nascido e sua família, a partir da implantação da primeira UTI neonatal em Florianópolis. Os sujeitos da pesquisa foram 13 profissionais de saúde que trabalhavam na UTI na década de 1980. Para coleta de dados utilizamos a História Oral, realizando entrevistas semiestruturadas. A análise dos dados foi baseada no referencial foucaultiano e resultou nos agrupamentos discursivos: A UTI neonatal possibilitando novas práticas no cuidado ao recém-nascido; Percepção da equipe de saúde sobre a família na UTI neonatal; 0 Hospital Infantil como marco no atendimento ao recém-nascido de risco em Santa Catarina. Os resultados desta pesquisa permitem afirmar que a implantação da UTI neonatal influenciou qualitativamente no cuidado ao recém-nascido e sua família, com o enfoque orientado para a sobrevivência do recém-nascido, e os reflexos desta experiência continuam presentes na atualidade.

Palavras-chave: UTI neonatal. Recém-nascido. Família. Cuidado do lactente. História.

\begin{abstract}
Qualitative study with social-historical approach which objective is to understand the history of transformations from practice in care of the newborn and his family, since the implantation of the first neonatal ICU in Florianopolis. The study subjects were 13 health professionals working in the ICU in the 1980s. For data collection Oral History were used, realizing semi-structured interviews. Data analysis was based on the Foucaultian reference and the following four discursive groups: The neonatal ICU giving new practices to newborns care, The health team's perception about the family in the ICU neonatal: resistance to new knowledge, Child's hospital as a reference for at risk newborn's care in Santa Catarina. The results of these researches allow to affirm that the implantation of neonatal ICU influence the qualitative in the care of newborn and his family, with focus oriented for the survival of the newborn and the consequences of these experiences are still current nowadays.
\end{abstract}

Keywords: Intensive Care Units Neonatal. Newborn, Family. Infant care. History
Resumen

Investigación cualitativa, con abordaje social e histórica cuyo objetivo fue comprender la historia de las transformaciones de las prácticas de cuidado al recién nacido y su familia, a partir de la implantación de la primera UTI neonatal en Florianópolis. Los sujetos de la investigación fueron 13 profesionales de salud que trabajaban en la UTI en la década de 1980. Para la recolección de información se utilizó la Historia Oral, realizando entrevistas semiestructuradas. El análisis de los datos fue basado en el referencial foucaultiano y dio lugar a tres formaciones discursivas: La UTI neonatal posibilitando nuevas prácticas en el cuidado al recién nacido; Percepción del equipo de salud sobre la familia en la UTI neonatal: resistencia a los nuevos saberes; El Hospital Infantil como un marco de referencia para la atención al recién nacido en riesgo en Santa Catarina. Los resultados permiten afirmar que la implantación de la UTI neonatal influenció cualitativamente en el cuidado al recién nacido y su familia, con el enfoque orientado para la sobrevivencia del recién nacido y los reflejos de esta experiencia continúan presentes en la actualidad.

Palabras clave: UTI neonatal. Recién nacido. Familia. Cuidado del lactante. Historia.

\footnotetext{
${ }^{1}$ Enfermeira. Doutora em Enfermagem. Professora do Programa de Mestrado Profissional Gestão do Cuidado da Universidade Federal de Santa Catarina. Pesquisadora do Grupo de Estudos de História do Conhecimento em Enfermagem e Saúde (GEHCES). Florianópolis - SC. Brasil. E-mail: robertanfr@hotmail.com; 'Enfermeira. Doutora em Enfermagem. Pós-Doutora pela Lawrence Bloomberg Faculty of Nursing at University of Toronto. Professor Associada da Universidade Federal de Santa Catarina. Lider do GEHCES. Pesquisadora do CNPq. Florianópolis - SC. Brasil. E-mail: padilha@nfr.ufsc.br
} 


\section{Cuidado ao recém-nascido em terapia intensiva em Florianópolis}

\section{INTRODUÇÃO}

A assistência ao recém-nascido passou por muitas transformações ao longo do tempo, sendo que a introdução de modernas unidades neonatais contribuiu significativamente na redução da morbimortalidade neonatal, e o advento de novas tecnologias ampliou a complexidade e abrangência do cuidado. ${ }^{1}$ Nos últimos anos, ocorreram grandes avanços científicos e tecnológicos, que proporcionaram inúmeras mudanças nas práticas de cuidado em unidades de terapia intensiva neonatais (UTINs) no Brasil, de certa forma acompanhando a tendência mundial. $^{2}$

0 berçário era um setor hospitalar que abrigava os bebês a termo e sem complicações, cujo contato com a mãe e os familiares era feito de modo descontínuo. ${ }^{3}$ Os primeiros berçários brasileiros surgiram em 1945. ${ }^{4}$ No Brasil, a prática de alojar conjuntamente puérperas e recém-nascidos não era frequente até a década de 70, e apenas as Santas Casas de Misericórdia acomodavam mulheres de baixa renda junto com seus filhos. A partir de 1997, o Ministério da Saúde instituiu a recomendação de que as crianças sem risco permanecessem ao lado de suas mães, e não mais em berçários. ${ }^{5}$

Há que se mencionar aqui que, em muitas Instituiç̃̃es, coexistiam o berçário tradicional e o berçário de alto risco, sendo que o berçário de alto risco era uma unidade que se diferenciava do tradicional, por se destinar ao atendimento dos recém-nascidos prematuros e/ou com complicações fisiopatológicas. Em termos amplos da atenção ao recémnascido, este tipo de unidade hospitalar era (e ainda é em algumas instituições brasileiras) especializada no cuidado ao neonato de risco, cujo objetivo principal era a sobrevivência deste bebê, sendo o cuidado focado na doença. Estas unidades foram criadas por conta de uma demanda e necessidade específicas, entretanto, nem sempre apresentavam estrutura adequada e normas idealizadas. ${ }^{6}$

Ao longo do século XX, por conta de toda uma conjuntura político-social, os berçários de alto risco transformaram-se em unidades de internação neonatal e unidades de terapia intensiva neonatal. ${ }^{7}$ Ainda é bastante confusa esta diferenciação do que foram os berçários de alto risco e o que são UTINs. A normalização oficial para o setor é relativamente recente e obscura. ${ }^{6}$ Digamos que as UTIs surgiram por conta de uma determinação político-assistencial, que começou a ser desenhada por volta da década de 80 .

Nosso interesse se volta especialmente para o entendimento das práticas e saberes instituídos a partir da implantação da UTI neonatal, enquanto unidade formalmente instituída, organizada e voltada conscientemente para um saber profissional que requeria especificidade, habilitação e princípios voltados ao objeto do cuidado, ou seja, o recém-nascido prétermo ou doente. Esta nova concepção de organização e ideário em torno do bebê de risco acontecia em concomitância com novas propostas ministeriais para o setor. Ao longo das últimas décadas, 0 conjunto de intervenções voltadas para a atenção ao período da gestação e primeiro ano de vida esteve sempre no centro das políticas públicas da saúde brasileira. ${ }^{8}$

Com base na literatura e nas políticas de atenção ao recém-nascido no Brasil, podemos constatar que, nos últimos anos, o universo científico vem se transformando no sentido de buscar a saúde integral, passando de uma visão mecanicista para um novo olhar, a visão de um todo dinâmico, indivisível, no qual as partes são essencialmente inter-relacionadas. ${ }^{9}$

Em Florianópolis, os saberes e práticas no cuidado ao recém-nascido, no âmbito hospitalar começaram a ser desenvolvidos nos berçários das duas tradicionais maternidades da cidade, a Maternidade Dr. Carlos Corrêa (1927) e a Maternidade Carmela Dutra (1955); nesta última existia também o berçário de alto risco, que, como já argumentamos, era uma unidade em que era prestada assistência ao recémnascido prematuro e/ou com intercorrências clínicas. Entretanto, oficialmente, as UTINs surgiram na cidade na década de 1980, sendo a primeira unidade instalada no Hospital Infantil Joana de Gusmão, em 1987. Neste contexto a pesquisa foi desenvolvida. ${ }^{1}$

A UTIN configura-se como um locus de produção de saber e constitui-se em ambiente terapêutico apropriado para tratamento de recém-nascidos de risco. Por entender que muitos dos saberes e práticas instituídas no cuidado ao recém-nascido de risco em nosso estado foram influenciados pelo atendimento nesta unidade, decidimos desenvolver o estudo com os profissionais que estiveram envolvidos com o processo de implantação da UTI. A inauguração desta unidade é a justificativa para a década histórica escolhida para esta pesquisa.

Ao buscar material bibliográfico e documentos científicos sobre o processo de implantação desta unidade, percebemos que há pouco ou quase nada registrado. Somado a isso, apesar dos avanços teóricos no cuidado ao recém-nascido, na prática, o que percebemos é que muitas vezes o modelo vigente ainda está centrado no modelo biomédico hegemônico. Portanto, 0 objetivo desta investigação foi o de compreender a história das transformações das práticas e saberes de cuidado ao recémnascido e família a par tir da implantação da UTI neonatal em Florianópolis.

Este estudo pretende contribuir para a compreensão de muitas ações de cuidado vigentes até hoje, bem como para refletir de que maneira os novos saberes são instituídos e são instituintes na prática pelos profissionais de saúde, valorizando a participação destes profissionais no processo de implantação das UTINs em Florianópolis e identificando novas possibilidades de cuidado aos recém-nascidos e suas famílias.

\section{MÉTODOS}

Pesquisa descritiva qualitativa, com abordagem sóciohistórica. Adotamos os princípios da Nova História, uma história para o tempo presente, que nos lança a conhecer e compreender uma história-problema, entender que qualquer sociedade 
proporciona uma história, em que passado e presente são iluminados pela discussão, pela análise de forças permanentes que atuam sobre as vontades humanas. Possibilita que se saibam quais as forças que estavam em cena em um dado momento, qual sua situação pós-acontecimento, se isso contribuiu para seu fortalecimento, enfraquecimento, ou se não proporcionou nenhuma mudança. ${ }^{10}$

0 local de realização da pesquisa foi o Hospital Infantil Joana de Gusmão, por ser este o hospital de referência para o atendimento de crianças e recém-nascidos de alto risco do estado de Santa Catarina e local onde foi implantada a primeira UTIN de Florianópolis, em 1987.

Para coleta de dados, utilizamos a História Oral, realizando entrevistas semiestruturadas com três médicos, cinco enfermeiras e cinco técnicos/auxiliares de enfermagem que trabalhavam na UTI geral e/ou UTIN na década de 1980. 0 número de participantes foi definido a partir da saturação dos dados. As entrevistas implicam a percepção do passado como algo que tem continuidade hoje, dentro de um processo histórico em andamento, cujo informante contribuirá com sua percepção dos fatos. ${ }^{11}$ Utilizamos fontes documentais, tais como livro de ocorrências, livro de atas de reunião e recortes de jornais. Estas fontes documentais foram utilizadas para validação das informações orais. A coleta de dados ocorreu de outubro de 2008 a março de 2009.

Para análise dos dados, utilizamos o método genealógico proposto por Michel Foucault, instigadas pelo convite e estímulo que o autor faz para olhar o nosso cotidiano de forma diferente. Foucault propõe o desenho de uma história nova, ou melhor, uma leitura histórica nova das ideias e do saber. ${ }^{12: 6}$ Entendemos que a genealogia, como procedimento explicativo, desconstrói as lutas no interior do discurso. Portanto, analisar o discurso seria dar conta exatamente disso: de relações históricas, de práticas muito concretas, que estão vivas nos discursos. Desta forma, procuramos explorar ao máximo o discurso dos atores que participaram do processo de implantação das UTINs, na medida em que as palavras são também construções; na medida em que a linguagem também é constitutiva de práticas/da realidade e produz, como o poder, inúmeros saberes.

A análise foi realizada a partir das transcrições das entrevistas e posterior leitura atenta, em que buscamos extrair os enunciados, tentando conferir-Ihes uma sistematização provisória. As entrevistas não permitiram dizer uma ou a verdade sobre as coisas e os fatos, mas pode-se considerá-las como a instância central que, somada a outras, trouxe informações fundamentais acerca do vivido e possibilitou uma interpretação (mesmo que provisória e parcial) da história das transformações das práticas e dos saberes no cuidado ao recém-nascido em terapia intensiva. Após compilação de todas as entrevistas, agrupamos os enunciados em três formações discursivas: A UTI neonatal possibilitando novas práticas no cuidado ao recém-nascido; Percepção da equipe de saúde sobre a família na UTI neonatal: resistência aos novos saberes; e 0 Hospital Infantil como marco no atendimento ao recém-nascido de risco em Santa Catarina.

0 projeto de pesquisa foi aprovado pelo Comitê de Ética em Pesquisa com Seres Humanos da Universidade Federal de Santa Catarina sob protocolo $n^{\circ}$ 242/08 FR 217903. Os participantes assinaram o Termo de Consentimento Livre e Esclarecido. Para garantir a anonimato, os sujeitos do estudo foram identificados com letras referentes às categorias profissionais e números (por exemplo, médico $M 1$, enfermeiro E3, técnico de enfermagem TE2 e auxiliar de enfermagem AE1).

\section{RESULTADOS E DISCUSSÃO}

Neste momento, apresentaremos os resultados desta investigação a partir de três agrupamentos discursivos, possibilitando ao leitor vislumbrar o percurso de análise dos dados na busca da compreensão da história das transformações das práticas de cuidado ao recém-nascido e sua família, em Florianópolis, a partir da implantação da UTIN.

\section{A UTI neonatal possibilitando novas práticas no cuidado ao recém-nascido}

A implantação das UTINs possibilitou aos recémnascidos de risco ter um local específico com profissionais capacitados para atender suas demandas de cuidado. Estas unidades contribuíram para detecção e tratamento precoce de doenças neonatais, avanços no conhecimento científico e aparato tecnológico, refletindo na redução da mortalidade neonatal. Entretanto, o foco do cuidado muitas vezes está direcionado apenas aos aspectos fisiopatológicos, em detrimento dos aspectos psicossociais.

A partir das entrevistas com os profissionais de saúde, podemos constatar que a implantação da UTIN possibilitou a produção do saber no cuidado ao recém-nascido.

O cuidado melhorou muito. As crianças tinham qualquer piorinha no berçário, já podiam descer por que tinham espaço. [...] foi a questão de abrir vaga. Muita criança saiu ganhando com isso, com a evolução da enfermagem, da medicina, dos equipamentos todos. Atresia de esôfago na UTI geral, saiam pouquíssimos! Na neo sai a maioria. Outra doença que morriam, a chance de viver era pouca, era a hérnia diafragmática. Melhorou muito com a neo. Sem falar em membrana hialina!?(TE2)

Depoimentos como este reforçam a importância do saber especializado, que fez emergir novos equipamentos, uma tecnologia de ponta, o médico intensivista e uma equipe de enfermagem capacitada e com habilidades no manuseio do recém-nascido.

A UTIN, enquanto espaço específico de atendimento do recém-nascido de risco vem se configurando como um campo de 


\section{Cuidado ao recém-nascido em terapia intensiva em Florianópolis}

conhecimentos e práticas, sendo este saber/fazer consolidado a partir das vivências/experiências do cotidiano do trabalho dos profissionais de saúde.

Eles aprendiam em serviço. Os novos que vierame acompanhavam para adquirir algum conhecimento, habilidade. Enão tinha nada de especificidade para recém-nascido. Agente aprendeu a cuidar de recémnascido, cuidando. Porque, não tinha (E3).

No início da implantação da terapia intensiva neonatal faltava um olhar científico para a assistência, faltava conhecimento para lidar com estes novos saberes e tecnologias, e a busca deste foi determinada principalmente com enfoque no processo patológico, no corpo doente e na sobrevivência do recém-nascido.

Em relação ao cuidado com o recém-nascido eu acho até que era bom, porque que a gente fazia tudo que podia com as condições que se tinha. Talvez a gente tivesse que ter um olhar mais cientifico para aquela assistência, era muito o fazer por fazer, acho. Não que a gente não soubesse o que estava fazendo, mas talvez faltasse um pouco de embasamento teórico, leitura, eu acho que era o que faltava para nós da enfermagem. O material era novo, as incubadoras eram novas, então tinha controle das temperaturas direitinho, da pele da criança, do ar das incubadoras, isso a gente fazia bem (E1).

Por outro lado, nos primórdios desta história, outros discursos sinalizavam para o cuidado sensível, humanizado e individualizado, que procura respeitar cada recém-nascido e família, que tem a sua história de vida e tem direito a uma assistência particularizada, que respeite as suas crenças e seus valores.

\footnotetext{
A tecnologia énecessária para proporcionarmelhora na assistência e, consequentemente, aumentar a sobrevivência, mas não substitui alguns cuidados em relação à humanização e ao respeito pelo paciente (M1).
}

Verifica-se nos depoimentos a necessidade de transformações no processo de trabalho nas UTINs, com vistas a ampliar o objeto de ação para além do corpo do recém-nascido, por meio da inserção da família, assumindo o recém-nascido como um ser de relações, rumo à construção de um novo modelo assistencial que visa à humanização da assistência neonatal.

Percebemos que com a implantação da UTIN, o profissional de saúde foi se apropriando do corpo do recém- nascido, tornando este objeto de seu cuidado. Foucault coloca que, ao controlar o corpo do doente, o profissional exerce um poder sobre o outro e que esta relação de poder deve ser entendida como produtiva, pois produz saber e constrói discursos. ${ }^{13} 0$ conhecimento de aspectos biológicos e fisiológicos desses bebês direcionou as práticas de atenção a este segmento populacional. As práticas de cuidado na UTI possibilitaram a operação de um saber científico sobre o corpo do recém-nascido, e este processo assemelha-se ao que ocorreu com outros desenvolvimentos da Clínica, é fruto do conhecimento parcelar e especializado.

\section{Percepção da equipe de saúde sobre a família na UTI neonatal: resistência aos novos saberes}

$\mathrm{Na}$ UTIN, os pais muitas vezes são vistos pelos profissionais de saúde como visita, ou seja, entram na UTI olham o seu bebê e recebem algumas informações. Ao entrarem na unidade pela primeira vez, os pais se deparam com um ambiente assustador, pouco acolhedor, com muitos aparelhos, e ficam chocados com a imagem de seu filho hospitalizado. É muito difícil para a família estabelecer um contato efetivo neste momento inicial. É fundamental que o profissional tenha compreensão desta questão para possibilitar uma aproximação dos pais com este ambiente e com seu próprio filho. Permitir o livre acesso dos pais na UTIN é o primeiro passo para facilitar este processo.

No entanto, o que percebemos com esta pesquisa é que, no início da UTIN, o hospital limitava a presença dos pais na unidade, estabelecendo o horário de visita.

\section{A família entrava, mas tinha horário. Não era tão liberado quanto é hoje (TE3).}

Olha, pelas regras do Hospital eles tinham um horário, das 3:30 as 4:30, se eu não me engano, para entrar. Somente, era um horário único. [...] 0 período da visita era aquele, mas não necessariamente eles podiam ficar uma hora (E3).

Outra questão presente nos depoimentos dos profissionais da UTIN do Hospital Infantil é que, além de limitar o tempo, restringia-se também o número de pessoas presentes. Apenas a mãe e o pai. Não era permitida a entrada de outros familiares.

A visita da familia sempre foi só uma pessoa (AE1).

Tinha uma resistência à participação da família, além da mãe (E4).

Nestes depoimentos fica explícito o poder que a equipe de saúde exercia sobre o pai e a mãe, ou seja, é o profissional de saúde que determina quem, quando e como poderá visitar o recém-nascido. Esta relação é exercida de maneira 
verticalizada, pois os pais estão à mercê dos profissionais de saúde que nesta relação são vistos como pessoas com o poder de salvar o seu filho. Assim sendo, os pais muitas vezes seguem as normas e rotinas da Instituição e não oferecem nenhum tipo de resistência. Os pais, na maioria das vezes, tornam-se meros expectadores dos cuidados especializados prestados pelos

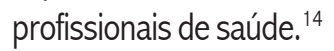

A presença da família nas UTINs muitas vezes é vista pelos profissionais de saúde como um problema, ou seja, é uma pessoa a mais para dedicar atenção. Além do que, os pais às vezes acabam disputando com o profissional o espaço ao lado do bebê. Também, frequentemente, a mãe representa uma avaliadora/fiscalizadora do cuidado. A equipe não se sente preparada para lidar com estas situações.

A presença dos pais é realmente muito difíiil. Então a gente sempre discutia tudo. [...] é mais trabalhoso? Mas dá mais satisfação (M2).

Quando instituímos novos saberes à prática de cuidado ao recém-nascido, percebemos um jogo de forças, em que alguns profissionais defendem condutas antigas como o isolamento do recém-nascido e o cuidado focado na doença, enquanto outros lutam por novas práticas, por abrir as portas da UTI para a família, favorecendo o vínculo afetivo, possibilitando que os pais enfrentem a hospitalização com menos temor e angústia.

Mudar a perspectiva tradicional de cuidado centrado na doença para uma abordagem cujo núcleo está na criança e na família dentro da UTI pode não ser algo fácil. É preciso derrubar as barreiras, eliminar a indiferença, fazer-se presente, não pela imposição de rotina, mas pela atitude de interesse e de preocupação. ${ }^{15} \mathrm{~A}$ filosofia do cuidado centrado na família reconhece a família como uma constante na vida da criança e os profissionais e o serviço de saúde como temporários e flutuantes.

Os discursos revelam que a presença da família na UTIN foi um processo, que as coisas foram mudando aos poucos, que foram instituídas novas práticas como a aproximação das mães, o estímulo ao colo, a posição canguru. Fica claro também que estas transformações foram ocorrendo influenciadas por alguns médicos e enfermeiros que assumiram a postura de lutar por esta questão.

A gente procurava, justamente, fortalecer esse vínculo. Porque já era triste; às vezes, nascia criança no interior, a mãe ficava, vinha o bebê e o pai ou vinha só o bebê com outro parente. Ea mãe às vezes ficava um tempo sem ver o bebê. Então a gente pelo menos tentava fortalecer o vínculo com a família (E5).

Eu acho que foi aos poucos que foi mudando. No início a gente não dava tanto valor a isso. 0 Hospital começou a se preocupar com a humanização, com a familia. Não foi uma coisa assim de uma hora para outra. Aos poucos a gente começou a ter contato com as mães, a colocar no colo, fazer bebê canguru. [...] todo esse contato foi aos poucos (TE2).

Questões como estas apontam para a necessidade de mudanças na organização das rotinas, que serão possíveis na medida em que os profissionais de saúde participem efetivamente em instâncias de gerenciamento, possibilitando assim a padronização de ações ou a legitimação de rotinas que foram desconstruídas ao longo do tempo. ${ }^{16}$

Com relação à presença da família, percebemos, a partir do discurso dos profissionais de saúde, que há muitas construções e desconstruções. Por um lado, o pai e a mãe só entram no hospital em horário de vista e são vistos por alguns profissionais como um problema; por outro lado, o discurso aparece em defesa da presença e participação da família, entendendo que esta prática é fundamental para o cuidado ao recém-nascido de risco.

É preciso entender de que forma as práticas são instituídas, como se instituíram as relações, que saber é dominante em determinado momento histórico, quais são as forças que estão em jogo, quais sujeitos detêm o poder e quais as resistências e os sujeitos resistentes. Procurar o que está por trás dos enunciados, limitar a presença dos pais na UTIN favorece quem? Qual a melhor prática para o recém-nascido? Para a família? E para o profissional de saúde? No caminho da transformação, percebemos que a família passou de um caráter de problema para ser vista como fundamental; esta é a gênese de uma grande virada no saber/fazer. ${ }^{17}$

\section{Hospital Infantil como marco no atendimento ao recém-nascido de risco em Santa Catarina}

A introdução das UTINs possibilitou aos recémnascidos de risco ter um local específico com profissionais capacitados para atender suas demandas de cuidado. Ao serem questionados sobre os motivos para abertura da UTIN, muitos profissionais referiram que a unidade era uma necessidade, que havia um aumento da demanda de recém-nascidos de alto risco. Outros relatam, ainda, que a UTIN era um sonho.

Na realidade o que motivou a abertura é que não existia um centro de neonatologia na grande Florianópolis. A gente recebia os pacientes e não tinha neonatologista suficiente, não tinha material adequado, não tinha uma forma de cuidar de recém-nascido. As crianças chegavam muito descompensadas porque vinham de todos os lugares para nós (E1).

Com a implantação da UTIN, aos poucos foi se constituindo um saber/fazer espećfico com relação às práticas no cuidado ao recém-nascido de risco. Assim, as práticas de 


\section{Cuidado ao recém-nascido em terapia intensiva em Florianópolis}

cuidado na UTI possibilitaram a operação de um saber científico sobre o corpo do recém-nascido. ${ }^{18}$

A UTIN, enquanto espaço específico de atendimento do recém-nascido de risco, configura-se como um campo de conhecimentos e práticas, sendo que este saber/fazer consolidase a partir das vivências/experiências do cotidiano do trabalho dos profissionais de saúde.

Como a UTIN do HIJG representou um marco no atendimento ao recém-nascido de risco, esta se consolidou como centro de referência em Santa Catarina, atendendo à quase totalidade dos nascimentos de alto risco ocorridos no estado. Desde a sua inauguração, esta unidade recebeu bebês provenientes das diversas maternidades de Florianópolis, assim como de outros hospitais de todo estado.

A UTI do Hospital Infantil Joana de Gusmão era referência. É como se a implantação do cuidado intensivo neonatal em Santa Catarina, em 87, fosse um marco tanto no saber, como nos cuidados, como nos resultados. Constituiu um divisor de resultados (M3).

A UTI estava sempre lotada. Sempre lotada, cirurgias cardíacas. [...] porque não tinha outra. [...] A referência era Florianópolis (TE4).

É importante salientar que os serviços especializados, como cirurgia pediátrica, neurologia, cardiologia, nefrologia, concentravam-se no HIJG. Com o passar do tempo, foi instituído um saber/fazer que direcionou as práticas de cuidado a este segmento populacional e possibilitou a abertura de outras unidades em diferentes regiões do estado. Como consequência deste processo os recém-nascidos de menor complexidade passaram a ser atendidos nas próprias maternidades, em berçários de alto risco e/ou em outras UTINs que foram criadas buscando a descentralização deste atendimento. Assim, também, novos profissionais foram adquirindo conhecimento, habilidade e destreza no cuidado ao recém-nascido.

Por ser esta a unidade de referência estadual, muitas vezes os profissionais de saúde que atuavam ali realizavam o transporte de recém-nascidos de outras unidades/maternidades para o HIJG. 0 transporte neonatal está intimamente ligado à história da UTIN do HIJG.

Nós íamos buscar. Eles ligavam dizendo, oh tem um paciente assim e assim. A gente arrumava a incubadora de transporte, outra que nós tínhamos aí. $E$ a gente ia buscar na Maternidade $X$, na Maternidade Y, no Hospital C (TE1).

Tudo drenava para cá, era a gente que fazia o transporte das crianças. A gente ia buscar crianças nas maternidades (E2).
Os profissionais que atuaram nesta UTIN desenvolveram durante muito tempo o transporte dos recém-nascidos principalmente das maternidades da grande Florianópolis. Esta prática de cuidado continua viva na memória de muitos profissionais, visto que era uma prática arriscada e muitas vezes inadequada, mas que com certeza possibilitou a sobrevivência de muitos recém-nascidos e a mudança no panorama do atendimento neonatal.

Outro grande marco na história desta unidade foi a disponibilização da área física, ou seja, de um espaço adequado ao atendimento neonatal. Muitos profissionais referem este como o maior problema na época da implantação da unidade e que perdurou ao longo do tempo por mais de 20 anos. Por ser um espaço improvisado e provisório, muitos profissionais tinham a esperança de que um dia teriam uma área específica e adequada a UTIN. Um sonho que se concretizou recentemente, quando em dezembro de 2008 foi inaugurada a nova área da UTIN do HIJG.

O ambiente físico? Era um aperto, e o que é pior, está exatamente igual a quando foi inaugurada. Com agravante que deve estar mais deteriorado. Mas está exatamente igual e desde que abriu ela tem uma proposta de ampliação, de mudança. Então, as incubadoras eram seis, não tinha espaço, o espaço era mínimo, às vezes quase encostava uma incubadora na outra, os respiradores chegavam a enroscar os pés, com toda parafernália que tem para uma UTI, aquilo era impossível (E1)

Apesar destes acontecimentos, é importante considerarmos que esta unidade representou um marco no cuidado intensivo neonatal catarinense e que os profissionais que contribuíram na implantação e implementação do cuidado nesta unidade foram fundamentais na instituição do saber, nas práticas de cuidado ao recém-nascido de risco e na instituição de novos sujeitos profissionais. Este processo vem resultando em uma redução da morbimortalidade neonatal e na aquisição de conhecimento científico relacionado ao recém-nascido.

\section{CONSIDERAÇÕES FINAIS}

0 caminho em busca da compreensão da história das transformaç̧ões das práticas de cuidado ao recém-nascido e sua família, a partir da implantação da UTIN em Florianópolis, mostrou-se pleno de idas e voltas. Com o discurso de olhar o passado, refletir sobre o presente e alçar voo para o futuro, os profissionais de saúde foram direcionando o movimento de reflexão. Na medida em que as palavras foram ditas, ia-se configurando uma rede de poder-saber-prática que foi instituindo ao longo do tempo o cuidado ao recém-nascido em terapia intensiva.

Ao tentar finalizar, percebemos que a história continua sendo construída pelos profissionais de saúde no dia-a-dia do 
processo de trabalho nas unidades neonatais, nas relações cotidianas entre recém-nascido-profissional-família.

Na tentativa de identificar como as práticas de cuidado ao recém-nascido vêm sendo construídas e consolidadas historicamente, percebemos que o saber nesta área de conhecimento foi fomentado a partir dos aspectos fisiopatológicos do recém-nascido e, por isso, alcançamos um rápido desenvolvimento tecnológico com equipamentos e medicações, que permitem hoje a sobrevivência de recémnascidos cada vez menores e mais prematuros. Entretanto, percebemos que, ao longo do tempo, o trabalho nas UTINs não poderia se concentrar apenas na sobrevivência dos neonatos, mas também na qualidade de vida destes recém-nascidos e famílias. Aos poucos foram sendo instituídas práticas no sentido de favorecer o desenvolvimento neurológico e de possibilitar a inserção da família na UTIN.

Nesta perspectiva, podemos compreender o poder produtivo, de acordo com a visão foucaultiana, como um fenômeno relacional que ocorre no exercício da convivência humana, em todos os momentos e em todos os espaços da vida social cotidiana, em que os indivíduos vivem, em que está o seu discurso e a sua prática de vida.

É importante destacar, também, que este estudo contribui na produção de conhecimento sobre o nascimento do recém-nascido de risco, acrescentando novos ângulos, aprofundamentos e perspectivas, especialmente, à prática do cuidado desenvolvido pelos profissionais da equipe de saúde em terapia intensiva. As facetas desveladas com esta experiência lançam rumos a outros caminhos, que poderão estimular investigações no sentido de modificar e melhorar a compreensão dos saberes e práticas no cuidado ao recém-nascido e sua família.

Consideramos também relevante afirmar que esta unidade representou um marco no cuidado intensivo neonatal catarinense e que os profissionais que contribuíram na implantação e implementação do cuidado nesta unidade foram fundamentais na instituição do saber, nas práticas de cuidado ao recém-nascido de alto risco e na instituição de novos sujeitos profissionais.

Os resultados desta investigação permitem afirmar que a implantação da UTIN influenciou qualitativamente no cuidado ao recém-nascido e sua família, com o enfoque orientado para a sobrevivência do recém-nascido, e os reflexos desta experiência continuam presentes na atualidade. Os saberes e práticas foram se transformando nas construções e desconstruções cotidianas no caminhar das UTINs em um determinado momento histórico e estão incorporados no pensar e no fazer na atualidade. Isso ocorreu em meio a jogos de poder/saber em movimentos que se entrecruzam, convergem e se opõem. Com embates e mediações, entre condutas antigas e novas práticas, com apropriações de saberes, processos de dominação, resistências sutis ou arrebatadoras, em um contínuo processo de ir e vir.
Ao findar este estudo, lançamos um desafio para futuras pesquisas: o que está se passando no momento atual, na construção de outros e novos saberes em meio ao processo poder/saber nesta seara? Como a Enfermagem está inserida neste jogo hoje? Os avanç̧os são claros e inegáveis. Os saberes e práticas no campo da neonatologia foram notáveis. Devemos dar um passo além, como profissionais da saúde, buscando formas criativas de expressão, abrindo brechas em meio aos padrões e práticas reinantes, contribuindo para novas práticas e novos valores, novos modos de pensar e de fazer no cuidado ao recém-nascido e sua família.

\section{REFERÊNCIAS}

1.Costa R. Saberes e práticas no cuidado ao recém-nascido em terapia intensiva na década de 1980 em Florianópolis. [tese de doutorado] Florianópolis: Programa de Pós-graduação em Enfermagem/UFSC; 2009.

2.Costa R, Padilha MI, Monticelli M. Produção de conhecimento sobre o cuidado ao recém-nascido em UTI Neonatal: contribuição da enfermagem brasileira. Rev Esc Enferm USP. [on-line]. 2010 mar; [citado 2011 abril 21]; 44(1): 199-04. Disponível em: http:/ www.scielo.br.

3.Monticelli M. Aproximações culturais entre trabalhadores de enfermagem e família no contexto do nascimento hospitalar: uma etnografia do alojamento conjunto. [tese de doutorado] Florianópolis: Programa de Pós-graduação em Enfermagem/UFSC; 2003.

4.Loyola MA. A cultura da puericultura. Est Cebrap. 1983 jul; 2(1): 40-6.

5.Ungerer RLS, Miranda ATC. História de alojamento conjunto. J Pediatr. $1999 \mathrm{jan} / \mathrm{fev} ;$ 75(1): 5-10.

6.Barbosa AP. Terapia intensiva neonatal e pediátrica no Brasil: o ideal, o real e o possível. J Pediatr. [on-line] 2004 nov/dez; [citado 2011 mar 15]; 80(6): 437-38. Disponível em: http://www.scielo.br .

7.Kamada I, Rocha SMM, Barbeira CBS. Internações em unidade de terapia intensiva neonatal no Brasil- 1998-2001. Rev Latino-am Enfermagem [on-line] 2003 jul/ago; [citado 2011 mar 16]; 11 (4): 436-43. Disponível em: http://www.scielo. br .

8.Carvalho M, Gomes MA. A mortalidade do prematuro extremo em nosso meio: realidade e desafios. J Pediatr. [on- line] 2005 mar; [citado 2011 fev 9]; 81 (1 supl): S111-S118. Disponível em: http:// www. scielo br.

9.Santos Neto ET, Alves KCG, Zorzal M, Lima RCD. Políticas de saúde materna no Brasil: os nexos com indicadores de saúde materno-infantil. Saude Soc São Paulo. [on-line] 2008 abr/jun; [citado 2011 abr 21]; 17(2): 107-19. Disponível em:http:// www.scielo.br .

10.Le Goff J, organizador. A história nova. Tradução de Eduardo Brandão. $4^{\text {a }}$ ed. São Paulo: Martins Fontes; 1988. 
11.Meihy JCSB. Manual de história oral. $2^{\mathrm{a}}$ ed. São Paulo: Ed Loyola; 2002.

12.Foucault M. Vigiar e punir. 4ªed. Petrópolis (RJ): Vozes; 1987

13.Foucault M. Microfísica do poder. $3^{\mathrm{a}}$ ed. Rio de Janeiro: Graal;1982.

14.Araújo BBM, Rodrigues BMRD. 0 alojamento de mães de recém-nascidos prematuros: uma contribuição para a ação da enfermagem. Esc Anna Nery. [on-line]. 2010 abr/jun; [citado 2011 abr 23]; 14(2): 284-92. Disponível em: http://www.scielo.br .

15.Molina RCM, Varela PLR, Castilho AS, Bercini LO, Marcon SS. Presença da família nas unidades de terapia intensiva pediátrica e neonatal: visão da equipe multidisciplinar. Esc Anna Nery. [on-line]. 2007 set; [citado 2011 abr 21]; 11(3): 403-08. Disponível em: http://www.scielo.br.

16.Souza KMO , Ferreira SD. Assistência humanizada em UTI Neonatal: os sentidos e as limitações identificadas pelos profissionais de saúde. Cien Saude Colet.[on-line]. 2010 mar; [citado 2011 abr 22]; 15(2): 471-80. Disponível em: http://www.scielo. br.

17.Costa R, Padilha MI. Percepção da equipe de saúde sobre a família na UTI neonatal: resistência aos novos saberes. Rev Enferm UERJ. [on-line]. 2011 abr/jun; [citado 2011 ago 15]; 19 (2): 231-35. Disponível em: http:// www.facenf.uerj.br.

18.Costa R, Padilha MI. O hospital infantil como marco no atendimento ao recém-nascido de risco em Santa Catarina (1987-2009). Texto\& Contexto Enferm. [on- line]. 2010 jul/set; [citado 2011 fev 15]; 19(3):469-78. Disponível em: http://www.scielo.br . 